\title{
Examining the Learning Efficiency by a Brain- Computer Interface System
}

\author{
J. Katona ${ }^{1}$, A. Kovari ${ }^{2}$ \\ ${ }^{1}$ Institute of Information Technology, University of Dunaújváros, Táncsics M 1/A, \\ 2400 Dunaújváros, Hungary, e-mail: katonaj@uniduna.hu \\ ${ }^{2}$ Institute of Engineering, University of Dunaújváros, Táncsics M 1/A, 2400 \\ Dunaújváros, Hungary, e-mail: kovari@uniduna.hu
}

\begin{abstract}
Brain research is one of the most significant research areas of the last decades, in which many developments and modern engineering technologies are applied. The electroencephalogram (EEG)-based brain activity observation processes are very promising and have been used in several engineering research fields. Objective: The main goal of this research was to develop a Brain-Computer Interface (BCI) system to observe the level of vigilance calculated by Think Gear-ASIC Module (TGAM1) technology and to evaluate the output with learning efficiency tests applied in cognitive neuroscience. Methods: The performance of the BCI system is evaluated in a comparative study. The BCI system was tested by thirty-two test subjects and the attention level output was compared by the Psychology Experiment Building Language's (PEBL's) Corsi block test ${ }_{P}$ CORSI) and $P E B L$ 's Ebbinghaus procedure ( $\left.{ }_{P} E B B I N G H A U S\right)$ tasks. Results: Using the BCI, we have shown statistically significant results between the $B C I$ and the conventional cognitive neuroscience tests. The correlation between the tests and the average attention of the BCI was slightly strong for ${ }_{P}$ CORSI Total Score $(r=.63, p<.01$ (2-tailed) and slightly strong for ${ }_{P}$ EBBINGHAUS Total Correct $(r=-.71, p<.01$ (2-tailed). The average level of attention measured by the BCI system during the ${ }_{P}$ CORSI test was $49.00 \%$, while in case of the ${ }_{P}$ EBBINGHAUS test it was $52.41 \%$ on all samples. Conclusion: The developed BCI system has a significant correlation with ${ }_{P} C O R S I$ and ${ }_{P} E B B I N G H A U S$ cognitive neuroscience tests. The BCI system is capable of observing attentional vigilance continuously. Significance: The developed BCI system is applicable to observe vigilance level in realtime while the level of attention depends on activities.
\end{abstract}

Keywords: brain-computer interface; Corsi block; Ebbinghaus procedure; electroencephalogram; PEBL; learning efficiency

\section{Introduction}

In order to understand the progress of studying, the human brain can be examined as a system, in which long-term changes occur, at least regarding fulfilling certain functions, that remain for quite a long period. During studying, this change in the 
brain means the alteration of the brain cells system and due to the modification of the connections between the cells, human functions could be better fulfilled. [1-3]

Efficient and successful learning, apart from understanding, interpretative [42-45] and problem-solving skills [46-49], is mainly determined by attention as a cognitive skill that also depends on emotional and motivational requirements and can be defined as a way of concertation on important information. [4-5, 53] Recently, relatively cheap and portable Electroencephalogram (EEG)-based signal processing devices have become available to observe the bioelectrical activities of the brain, with which the electrical signals generated by the activities of the brain can be measured and processed [51]. These EEG biosensors are able to digitally register and process the electrical activity of brain neurons in real time. The strength of the brainwaves could be determined by The Fast Fourier Transform (FFT)-based evaluation of information, from which the level of attention could be concluded.

If the attention of students can be examined by a device that measures brain and bioelectrical activity, the features of determining the efficiency of learning can be inferred. By observing the attention level, the most important factor in studying becomes continuously measurable, from which the efficiency of learning through the lesson can permanently be observed and that means continuous feedback could be received about the efficiency of teaching and learning processes. For instance, after recognising the decrease of the efficiency value, the method of knowledge transfer can be changed by using more effective teaching methods or even by keeping a relaxing break.

\subsection{Human-Computer Interfaces and Cognitive Infocommunication}

The fields of infocommunications, media informatics and media communications has developed a lot in the last ten years. The evolution of these disciplines has resulted in newer fields within this topic. Baranyi and Csapo summarize the scopes and goals of cognitive infocommunications (CogInfoCom) in [53], [54].

The human-machine interaction is described as the performance of the communication and feedback between humans and technical systems. This cognitive based communication is generally solved by IT systems. The humanmachine interface helps the human being operate the machine, control actuators and handle the machine's use. On the other hand the human has to sense and exchange information; communicate with the machine which informs the user about the operation conditions of the machine. But from another perspective everything that communicates with humans by cognitive level using IT system can be expressed as CogInfoCom. CogInfoCom covers several disciplines appearing in applications and research areas also. CogInfoCom is available technology from socio-cognitive ICT [55-65] to cognitive aided engineering [66-77] and its related 
aspects in terms of online collaborative systems and virtual reality solutions [7880], teaching-learning [81-86] and human cognitive interfaces such as braincomputer interfaces (BCIs) [87-92] and medicals [93-96].

\subsection{The Brain-Computer Interface}

Nowadays BCI is the most developing multidisciplinary research area, which only goes back two decades. The design, development, implementation, and application of these devices are in the spotlight. The aim of the first BCI researchers was to create a direct communicational channel for those in need to help their quality of life, particularly of those suffering from devastating conditions, such as amyotrophic lateral sclerosis (ALS), spinal cord injury, stroke and cerebral palsy. [6-13]

$\mathrm{BCI}$ is a direct functional interface between the brain and the computer or another device that can observe and decode the electromagnetic signals of brain activities and transfers the received information towards an external device $[6,7,50]$. Noninvasive BCIs have been an active research area; they include EEG, Near-infrared Spectroscopy (NIRS), functional-MRI (fMRI), among others [22-24]. The most popular BCI systems are based on scalp EEG signals due to their low cost, and to the fact that they are non-invasive and easy to use.

Certain functions of brain activity are known due to the results of brain research and cognitive neuroscience [25]. Understanding the operation of the brain is of great importance in measuring and interpreting brain waves [26]. The electrical and magnetic phenomena of neural function can be observed during brain operation using a routinely applied method called electrophysiology [27]. The most common method of electrophysiological observation is electroencephalography, whereby the brain electrical signals generated by brain activities are measured and registered by biosensors [28].

Brain cells communicate by sending electric signals to each other; the more signals are sent, the more electricity the brain will produce, and an EEG can measure the pattern of this electrical activity. The EEG signals are mostly processed by the quantitative EEG (QEEG) method, in which the frequency spectrum of the EEG signals is observed [29]. Conducting an EEG has previously required complex, expensive, large and immobile equipment.

As a result of ongoing technological developments in recent years, mobile EEG biosensor-based embedded devices are now available for use in new applications, for instance in entertainment, controlling or for educational purposes. In these applications, the connection between the brain activity observed by the EEG and the induced function is effectuated by a BCI [30].

The latest BCIs applied with biosensors and modern signal processing units have become cheaper and more portable because of their simple structure, while their 
accuracy is similar to that of the clinical EEG devices [10, 31, 32]. The research trends that deal with BCI systems include many other application areas of use, for instance, using BCI for observing the brain's procession of information [13-16] or implementing navigation tasks [17-20]. Beside these, the implementation of such a complex system and the observation of its efficiency can greatly be used in the field of education either among interested students or in teacher-managed projects. [21].

The research in this article deals with forecasting the efficiency of attention-based learning with the established BCI system, of which applicability is compared to the cognitive tests for the efficiency of learning applied in cognitive psychological examinations, i.e., the PEBL's Corsi block test ( $\left.{ }_{\mathrm{p}} \mathrm{CORSI}\right)$ and PEBL's Ebbinghaus test (pEBBINGHAUS).

\section{An Overview of the BCI System}

A BCI system acquires EEG signals from the human brain by an EEG headset, which is filtered, pre-processed and the features of the signals are extracted, classified and transferred to an output signal and visualized by a computer application interface (Fig. 1). This output signal relates to the brain activity of the user and contains the information detected by brain activities. The user receives feedback from the output or the application interface, so the BCI system realizes a closed-loop system.

During the EEG, the electrodes are placed on different symmetrical points of the skull, where the conducts could be evolved as unipolar or bipolar. In unipolar evolving, an active and a null-reference electrode are used, while in case of bipolar measurement, the potential alteration between two different electrodes is conducted. A correlating system known as the internationally accepted 10/20 electrode arrangement system (Fig. 2) was made in connection with the suiting of the electrodes, in which anatomical correlating points are defined. For the unequivocal identification of conduct fields, every point on the human cranium has been given a letter (Fp, F, T, C, P, O) and a numerical feature, where the letters identify the lobe position (Frontal polar, Frontal, Temporal, Central, Practical, Occipital), and even numbers identify the right, while odd numbers the left hemisphere. [29, 31, 32] The electrical activities of the brain, the electrical signals resulting from ionic current flows within the neurons, can be measured by the EEG by placing a sensor on the scalp [29, 31, 32]. The frequency spectra of brain signals are typical in different mental states $[26,52]$ and can easily be determined by digital signal processors using Fourier-transform, for example, NeuroSky [31]. This spectrum of the brain waves is very sensitive to the mental and emotional states of the brain, so this attribute is used to monitor mental activity [26]. 


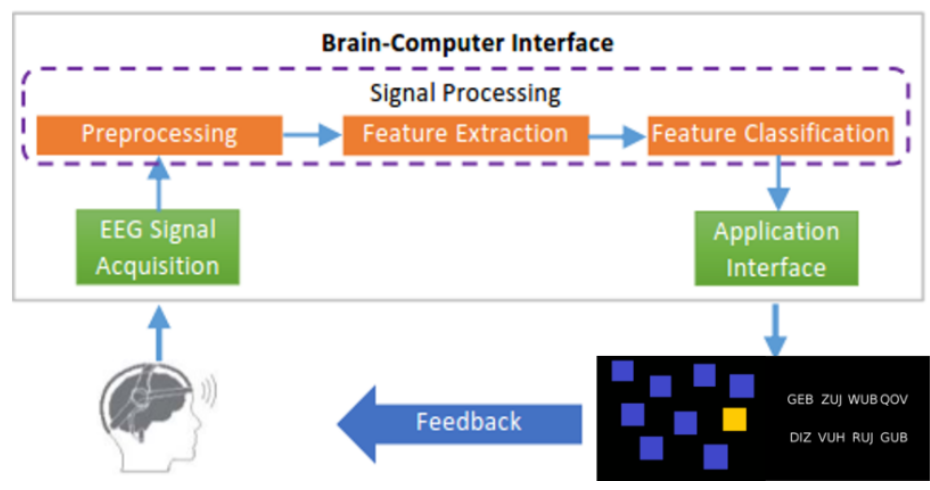

Figure 1

BCI model applying ${ }_{\mathrm{P}} \mathrm{CORSI}$ and ${ }_{\mathrm{P}}$ EBBINGHAUS

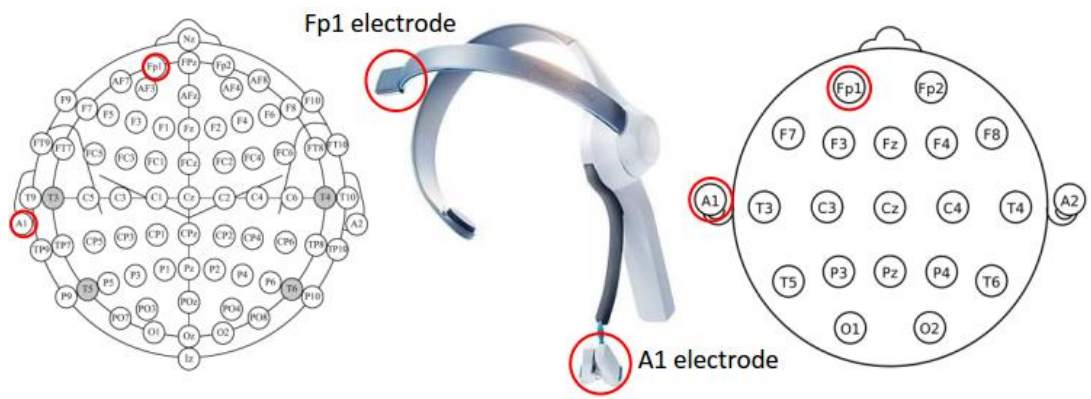

Figure 2

The international 10/10 and 10/20 system for EEG electrodes with the electrodes of the NeuroSky MindWave EEG headset highlighted in red circles

\subsection{The NeuroSky EEG-based MindWave Headset}

NeuroSky has been developing EEG-based measuring devices for years with the co-operation of some universities, for example, Stanford University, Carnegie Mellon University, University of Washington and University of Wollongong [33]. The MindWave EEG headset is a lightweight, portable device with wireless communication [34] and unipolar conduction. Fig. 2, illustrates the locations of the electrodes of the MindWave EEG headset in the 10/20 system and in a later $10 / 10$ system. The active electrode both in the 10/10 and 10/20 systems measures the activity of the frontal lobe that can be executed in the position of Fp1, slightly left from the midline, while A1 position, the left earlobe, was chosen for the reference point. 


\subsection{The Evaluation of Vigilance Level Based on Brain Waves}

The connection between attention and brain waves was observed in the 1970s and an EEG-based attention analyser was patented [35]. The method applied for determining the intensity of attention is based on the examination of the Power Spectrum Density (PSD) determined by the Discrete Fourier Transform (DFT) algorithm of brain waves. The spectrum can be calculated using samples of the brain signals. The sequence of $N$ complex numbers $x_{0}, x_{1}, \ldots, x_{N-1}$ can be transformed into a sequence of complex numbers with periodic $\mathrm{N}[39,40]$ :

$$
X_{k}=\sum_{n=0}^{N-1} x_{n} e^{-i 2 \pi \frac{n}{N}} k=0, \ldots, N-1
$$

where $\mathrm{X}_{\mathrm{k}}$ encodes the amplitude and phase of a sinusoidal component of function $\mathrm{x}_{\mathrm{n}}$, which is a complex number. The intensity of brain waves and the aim of this research, the magnitude of attention, can be determined.

The inverse of it:

$$
\mathcal{X}_{n}=\frac{1}{N} \sum_{n=0}^{N-1} \mathcal{X}_{k} e^{i 2 k \pi \frac{n}{N}}
$$

The continuous Fourier transform could be evaluated over a finite interval rather than from $-\infty$ to $+\infty$ if the waveform is periodic. Similarly, if there are only a finite number of sampled data, the DFT handles the data as if it is periodic. (samples 0 to $N-1$ is the same as $N$ to $2 N-1$ ). Therefore, DFT is evaluated for the fundamental frequency $\frac{1}{N T} \mathrm{~Hz}, \frac{2 \pi}{N T} \mathrm{rad} / \mathrm{s}$.

Performing DFT needs a lot of calculation, but this can be decreased by optimizing the algorithm. In case of DFT, calculation demand is $O\left(N^{2}\right)$, while performing the FFT process, it could be decreased to the $O(N \cdot \log N)$ value (where $N$ is the data size). By FFT algorithm, brain bioelectric spectrum can be calculated, where the strength of certain brain waves specific to the encephalic operation could be defined.

NeuroSky developed a ThinkGear measurement technology to calculate the PSD using 512 samples per second sampling frequency and eSense Attention meter algorithm to indicate the intensity of attention, which occurs during intense concentration. The device amplifies and digitalizes the voltage difference (to achieve better common mode rejection) between a single dry sensor on the forehead and a reference on the ear. The brain signal is filtered by analog and digital, low and high pass filters in the $1-50 \mathrm{~Hz}$ range. Each second, the signal is analysed in the time domain to detect and correct noise, a standard FFT is performed, and finally, the signal is rechecked for noise and artifacts in the frequency domain to get brainwave strengths and eSense Attention and Mediation values. eSense algorithm is dynamically learning, so ThinkGear sensors are able 
to operate on a wide range of individuals, and on a wide range of personal and environmental conditions.

ThinkGear has been compared with Biopac system as a reference, which is a wellknown wet electrode EEG system widely used in medical and research applications. Data were fixed simultaneously and during the study, the sensors were fixed to identical places near to each other. The determined performancespectrum, which was determined by the measuring data supplied by the two instruments, was compared in a $1-50 \mathrm{~Hz}$ frequency range, which is the frequency range of certain typical brain wave types. The result they showed was that the correlation factor supplied by the two devices among the performance-spectrum is bigger than 0.7 , and it is determinable that the information supplied by the two instruments are nearly identical [32].

eSense Attention meter output value ranges from 0 to 100 . Values between 40 to 60 are considered "neutral", 60 to 80 "slightly elevated", 80 to 100 are considered "elevated", meaning they are strongly indicative of heightened levels of attention. Values between 20 and 40 indicate "reduced" levels of the eSense and 1-20 indicates "strongly lowered" level. An intense meter value of 0 is a special value indicating the ThinkGear is unable to calculate the eSense level.

\subsection{The Implementation of the BCI System}

A Windows Forms Application Interface has been developed to evaluate and visualize the brain wave data of the MindWave EEG headset. This BCI program can run on MS Windows and has been written in C\#. Microsoft Visual Studio was used to implement the program, which is a developing environment that supports modern object-oriented programming. During the software implementation of the BCI, the system development life cycle (SDLC) terminology was applied, where certain software development cycles could be separated and defined well, making the development process easier to follow. During performing the software, we created the clear code, in order to make an easy-to-overview and easy-to-maintain application.

\subsubsection{The Structure of the Implemented BCI System}

The application consists of seven classes and their connections (Fig. 3). The base class of the application is the PacketHeader, which features contain all data values sent by the EEG headset that are not brain wave values in feature type method (Fig. 3). SYNC1, SYNC2: these byte values indicate the beginning of fresh data packs, and their value is 0xAA (decimal 170). pLENGTH: A Packet's Data Payload (PAYLOAD) indicates the section length in a byte. The complete length of a pack sent by the EEG headset is always pLENGTH +4 . POOR_SIGNAL_Quality is an unsigned one-byte integer value, which indicates the quality of the signal measured by the headset. The value range could be $0-255$, 
the bigger the number, the louder the noise. vLENGTH ("Value Length") only appears if the pack differs from the expected value. ASIC_EEG_POWER_INT is a value that specifies the representation of brain wave values in the sent pack. Storing brain wave values is implemented in an extension of the PacketHeader class, in the BrainWave class, where data could only be reached with the help of feature data (Fig. 3). The perceived data are processed in the SignalAcquisition class. The Visualize class implements functions responsible for objects specifying visualization, attribute values and changing events. The EEGSignalPower class shows the display of the on-screen information. Data storage and their statistic procession are determined in the Storage Class.

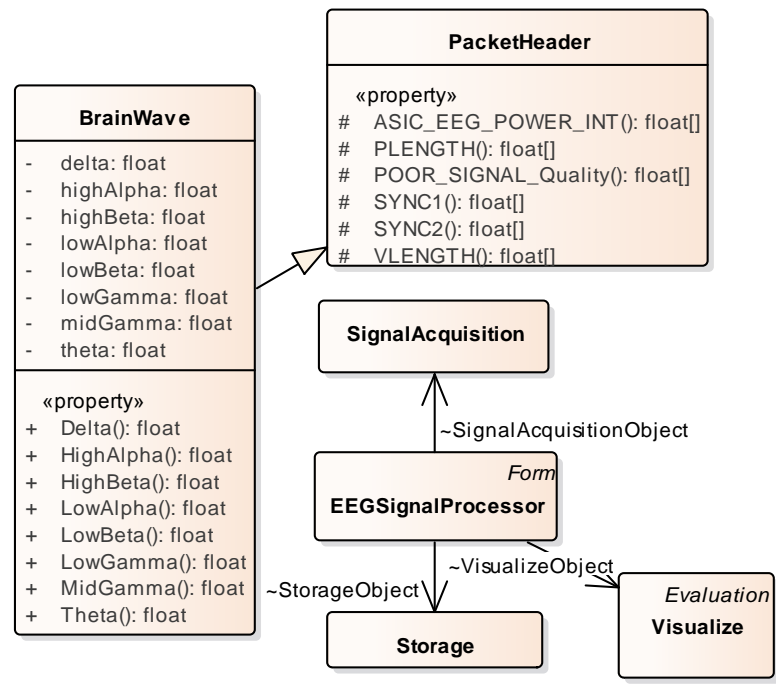

Figure 3

The structure of the implemented BCI software-based UML (Unified Modeling Language) class diagram

\subsubsection{The Functions of the Implemented BCI System}

The application is responsible for supplying different functions. These functions contain handling appropriate serial communication, receiving data packs from the EEG headset at appropriate intervals as well as processing them according to the protocol, visualizing brain wave values of the data pack in a particular time and continually, storing of the brain wave values in a pre-determined data structure, or providing pre-determined statistics from the brain wave values for further use.

The pseudocode of one of the main functions of the implemented software could be seen in Figure 4. This method is responsible for the appropriate procession of the incoming data packs and their refreshing according to the sampling time (1 s). 


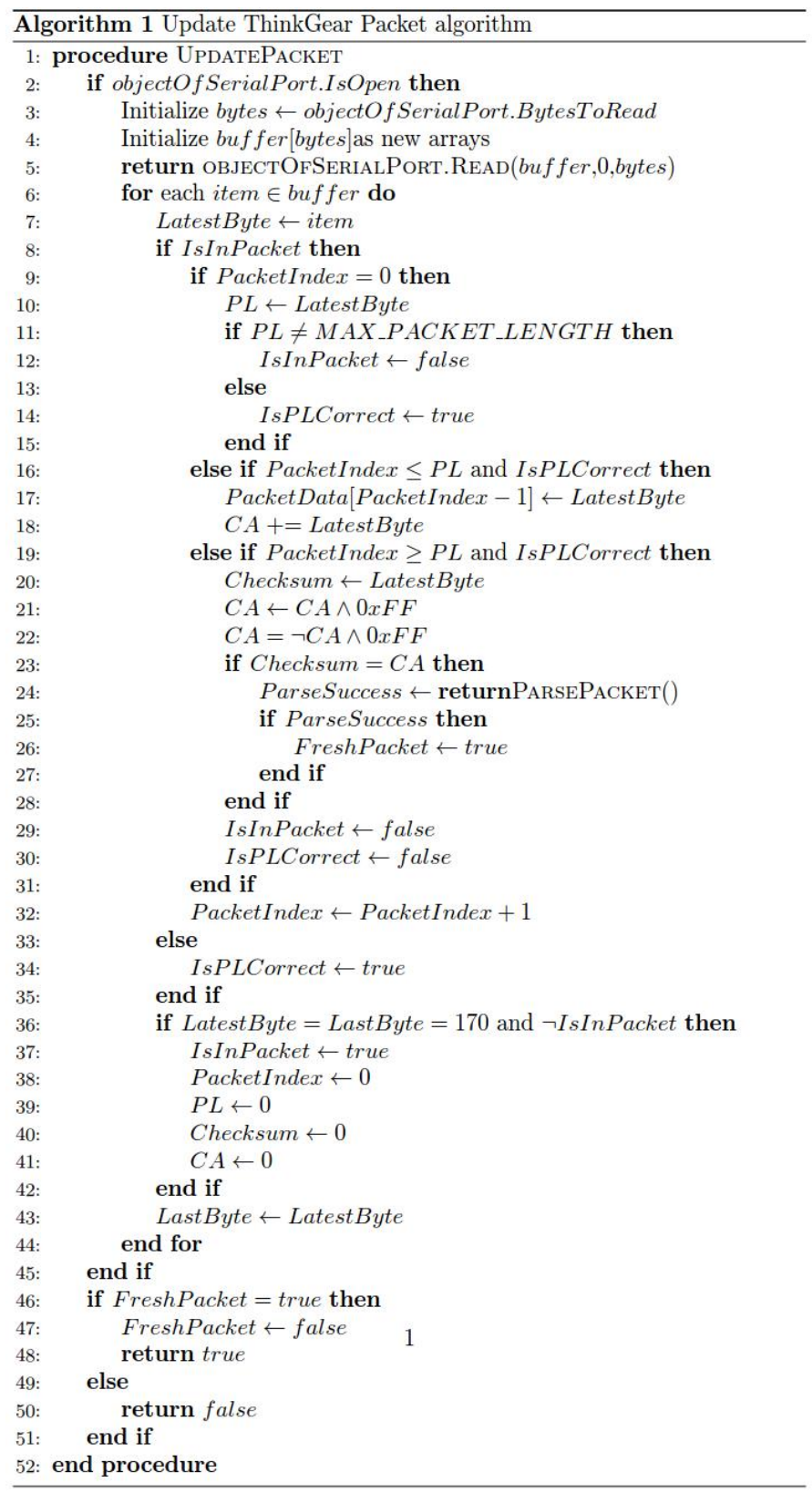

Figure 4

One of the main functions of the procession of the data pack from the MindWave EEG headset. Require: $\$$ IsInPacket $\$=$ false, $\$$ HasPower $\$=$ false, $\$$ IsPLCorrect $\$=$ false, $\$$ PacketIndex $\$=0, \$ P L \$=$ $0, \$ C A \$=0, \$ C h e c k s u m \$=0, \$ M A X \backslash$ PACKET $\_L E N G T H \$=32$; Comment $\{$ PL $=$ PacketLength; IsPLCorrect $=$ IsPacketLengthCorrect $; \mathrm{CA}=$ CheksumAccumulator $\}$ 


\section{Materials and Methods}

According to the objectives of the research, to analyse the experiment on the efficiency of studying, we have to be able to measure effectiveness itself. The aim of the measurement is examining memorizing, which means storing certain information in the long-term memory.

The items of information that are emphasized during attention do not faint but are moved to the short-term memory [41], which refers to the fact that attention decides which information is important and which one is not. The least important ones are evaluated at a lower level of information procession and after a while they faint and become forgotten. As coded information can get into the long-term memory only through the short-term memory, all data stored in the short-term memory has a key role in the learning process and knowledge acquisition. The information put into the short-term memory is mainly determined by the level of attention, therefore, there is a direct connection between learning and paying attention. Based on these facts, short-term memory tests could be used for examining knowledge acquisition and learning process by the mediation of attention. In the following, ${ }_{\mathrm{P}} \mathrm{CORSI}$ and ${ }_{\mathrm{p}} \mathrm{EBBINGHAUS}$ tests implemented in PEBL environment will shortly be demonstrated for the examination of work memory, viz., short-term memory and learning skills.

The BCI system was tested by test subjects, and the vigilance level output of the BCI system was compared to ${ }_{\mathrm{P}}$ CORSI and ${ }_{\mathrm{P}} \mathrm{EBBINGHAUS}$ tasks. The aim of this research is to define the strength and direction of the connection between the results of PEBL's memorizing efficiency tests and the attention level determined by the EEG-based BCI equipment.

\subsection{The ${ }_{\mathrm{P}}$ CORSI and the ${ }_{\mathrm{P}} \mathrm{EBBINGHAUS}$ Tests}

In neurobehavioral studies, the Psychology Experiment Building Language (PEBL) environment is widely used for implementing algorithms of test procedures. Most experiments are carried out with the use of shapes, texts, letters that appear on the computer screen while using computer peripherals (mouse, keyboard) for fixing the reactions given to the experimental target stimulus of the test subject. [38]

${ }_{\mathrm{p}}$ Corsi is a measuring test where the test subject is sitting in front of the computer with a black background screen; on which nine identical squares appear in different positions keeping one second breaks (Fig. 5). After the test is started, some squares in a pre-determined order are chosen by the program and the task of the subject is to click on the same squares in the same order. If the test subject can repeat two out of two series, the number of the blocks increases with another one until the number of successfully repeated series falls below two. With this test, we could get information about how precisely the test subject can recall the right 
order by using the information stored in the short-term memory with the help of attention.

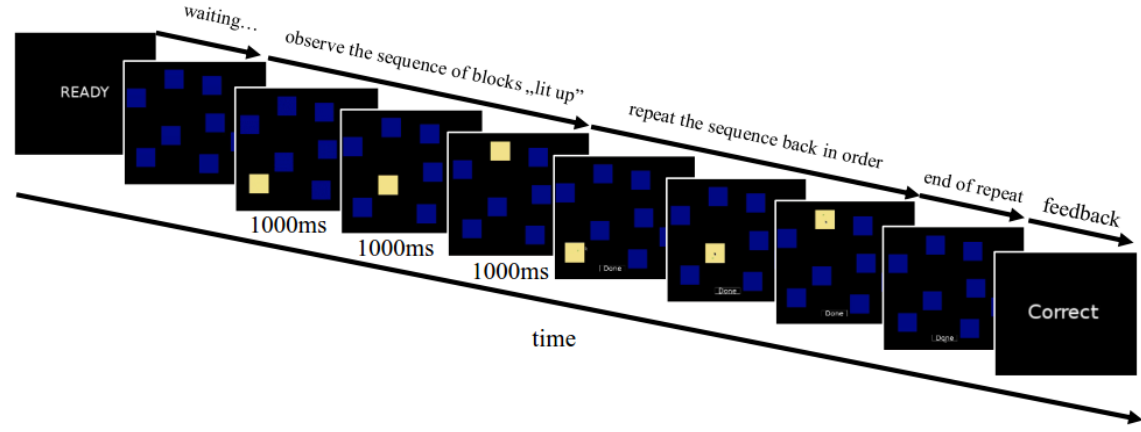

Figure 5

The block sequence was presented in the encoding phase, and the test subject recalled the sequence immediately afterward

${ }_{\mathrm{p}}$ EBBINGHAUS is a short (5-10 minutes) examination based on Hermann Ebbinghaus' self-experiments. During the test, the test subjects have to study eight different three-letter words (Fig. 6). The software generates words that are nonsimilar to words of any mother tongues or any words that may appear in the languages spoken by the subject. The words are built up of three letters, in which the first and the third characters are consonants and the middle one is a vowel. The list of the eight words is repeated by the program until the test subjects are able to recall them correctly twice. After that, the software generates a new list and repeats that again until it is recalled flawlessly twice by the test subjects. At the end of the successful recall of the two lists, the software goes back to the first list and the process starts again. The test ends when the test subjects can correctly recall both lists twice.

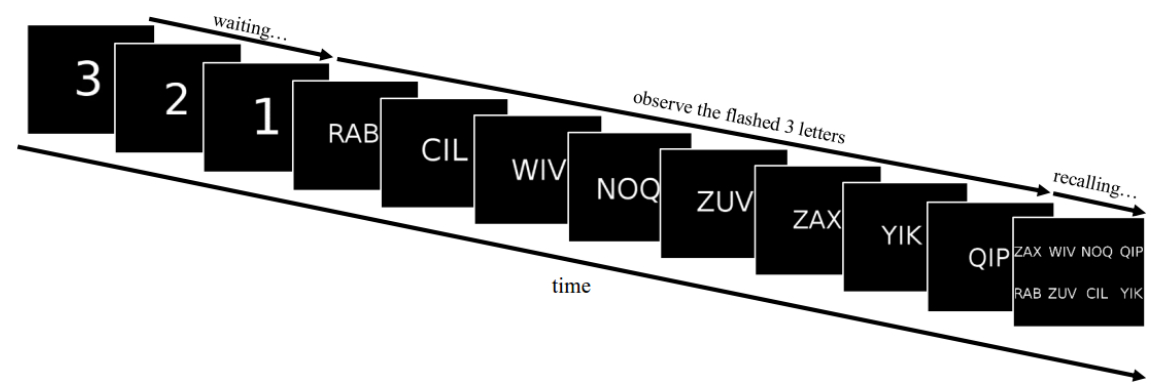

Figure 6

After flashing eight 'words' of three letters, the test subjects have to recall them in the correct order. The 'words' are repeated until the participants are able to recall them correctly twice. 


\subsection{The Participants}

In this experiment thirty-two high school students participated. All subjects were healthy, with no past history of psychiatric or neurological disorders. The age distribution was $14-18$, the average age was 16.2 , range $\pm 1.4 ; 47 \%$ girls.

\subsection{The Procedures}

During the procedure, first the ${ }_{\mathrm{p}} \mathrm{CORSI}$, then the ${ }_{\mathrm{p}} \mathrm{EBBINGHAUS}$ test was accomplished. The testing was carried out in one separated room, in which five or fewer participants could be tested at the same time. Before the experiment, the test subjects had to put the EEG headset on, and then the details of the procedures were described to them. After the introduction and the calibration of the device, the test subjects could start the tests. (Fig. 7a, b) Testing was performed using a desktop computer running Windows 10, using 22.0" computer screen at a resolution of 1920x1080 with 90\% contrast (responses were using keyboard and mouse).

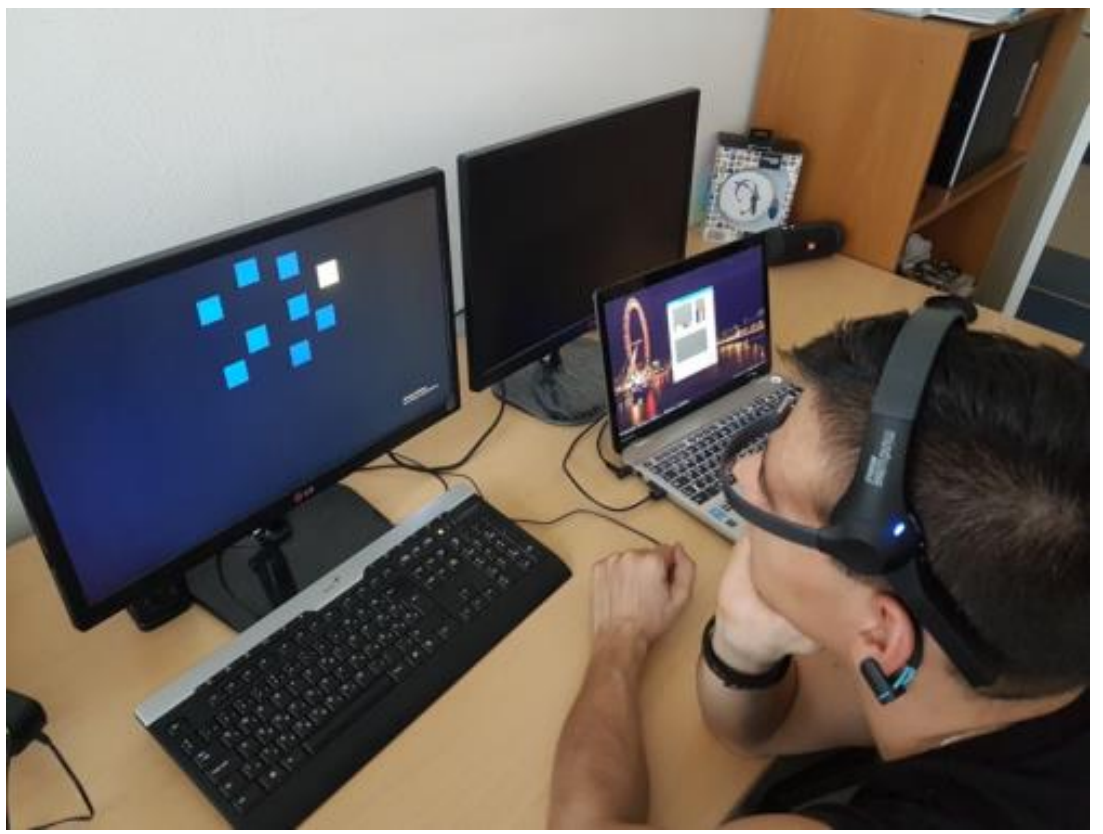

Figure $7 \mathrm{a}$

A test subject doing the ${ }_{\mathrm{P}} \mathrm{CORSI}$. The data measured by the EEG headset are continually being monitored. 


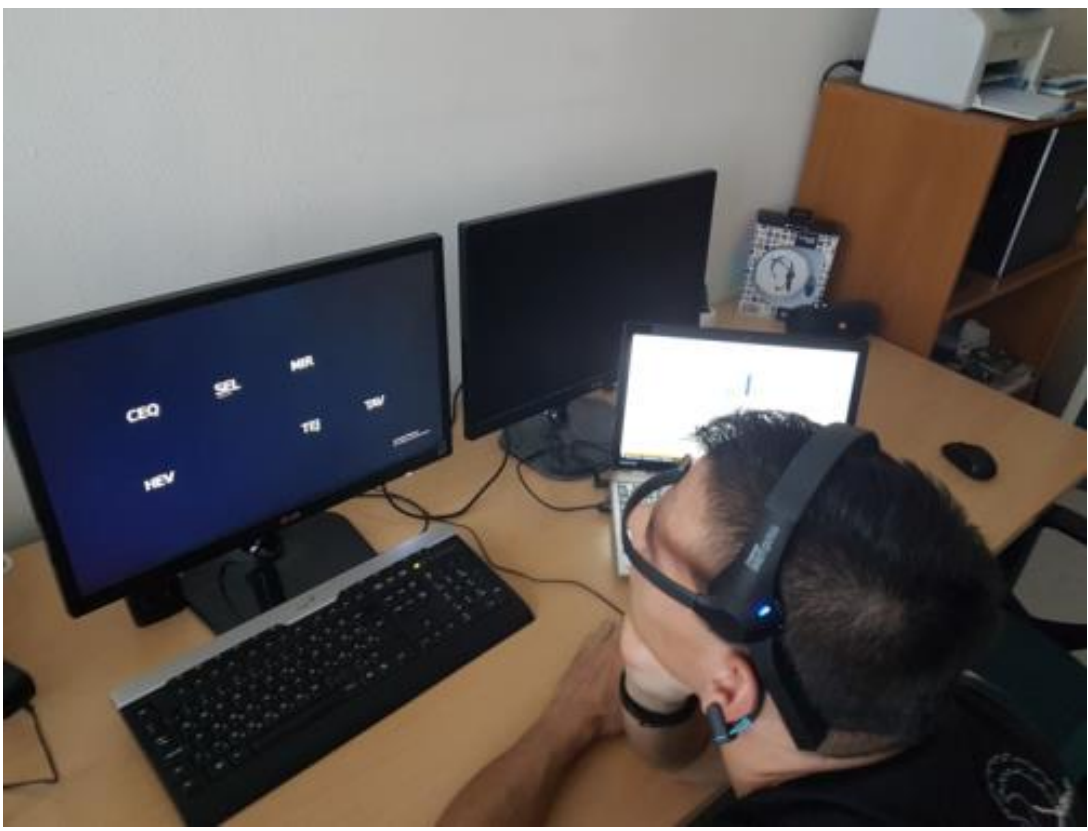

Figure $7 \mathrm{~b}$

A test subject doing the ${ }_{\mathrm{P}}$ EBBINGHAUS tests. The data measured by the EEG headset are continually being monitored.

\subsection{Statistical Analysis}

The statistical analysis of PEBL tests was made by an interval scale, while in case of the BCI, it was done on an ordinal scale with SPSS 23 (SPSS, Inc., Chicago, IL) program pack. As an ordinal scale was defined for the BCI, in the use of the BCI results, non-parametric tests were applied, while in connection with PEBL test results, if parametric test conditions were fulfilled, parametric tests were done. To define the difference between the morning and afternoon test results of the psychological tests, since test subjects in PEBL tests are independent of each other, with the exception ${ }_{\mathrm{P}} \mathrm{CORSI}$, the samples showed normal distribution and at least were scale typed, furthermore, as the standard deviation homogeneity is not needed to be done in case of related patterns, we used related-pattern t-test, where the effect size was determined by Cohen d-value. As during the psychological tests, in case of defining the differences between the morning and afternoon results of the average attention level measured by the BCI system, the variables were measured on an ordinal scale and the test subjects were independent of each other, Wilcoxon signed-rank test were applied, where the effect size was determined by the $\mathrm{z}$-value of the test statistics and the ratio of the root of the total sample element number. In case of the applied statistical tests, $p<0,05$ value was determined as significant. 


\section{The Results and Discussion}

During our primer type quantitative experiment, we examined dependency relationship and collected metric data, from which we analysed correlation. The aim of our next research was to find connections with the help of an independent and a dependent variable between ${ }_{\mathrm{P}} \mathrm{CORSI}$ and the BCI and ${ }_{\mathrm{P}} \mathrm{EBBINGHAUS}$ and the BCI system-specified attention level results.

\subsection{Comparing the Results of ${ }_{\mathrm{P}}$ CORSI and BCI}

The aim of the examination and evaluation is to investigate the correlation between two variables, an outstanding result of the ${ }_{\mathrm{P}}$ CORSI test and the average attention level provided by the BCI system. The correlations and relationships between the results of the obtained test and the measurement provided by the BCI system can be estimated and evaluated on the whole sample, i.e., on all test subjects.

The strength of the connections was determined by one of the results of the ${ }_{\mathrm{p}}$ CORSI test, which is an outstanding value, the most typical parameter of the test result. To examine the correlation between the measurement results, Spearman's correlation was used with two-sided tests, since in case of the BCI variable, an ordinal scale type was determined, and our data changed monotonically. During the test, the difference between the morning and afternoon results were evaluated in case of each subject so that the differences in individual ability did not play a role in the learning test results, but the level of attention of the morning and afternoon tests did.

In the ${ }_{\mathrm{p}} \mathrm{CORSI}$ test examining the efficiency of memorization, comparing the change in the results of the more alert and more tired state tests to the change of difference of the mean value characteristic of attention determined by the data processed by the BCI system, a significant positive correlation (Fig. 8) where $r_{s}=0.630 p<0.01$ (2-tailed) can be shown. 


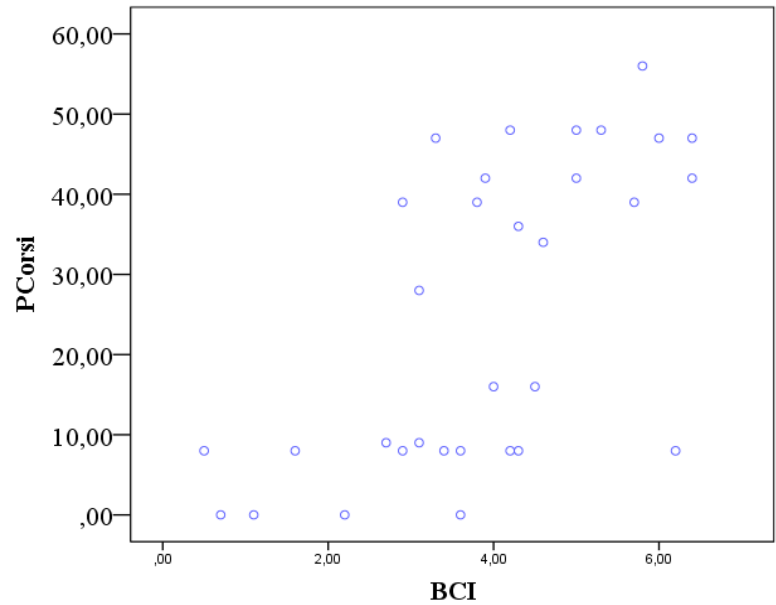

Figure 8

The ${ }_{\mathrm{P}}$ CORSI test showed a significant positive correlation with the value of differences of average level of attention determined by the BCI system

A more detailed overview of correlation evaluation is given in Table 1.

Table 1

Spearman-correlation analysis for the whole sample $(\mathrm{N}=32)$ on the results of the ${ }_{\mathrm{P}} \mathrm{CORSI}$ test and the difference of the mean value characteristic of the level of attention determined by the BCI

\begin{tabular}{ccccc}
\hline \hline Period & Test & $M \pm S D^{I}$ & Correlation & $p$-value \\
\hline $\begin{array}{c}\text { morning- } \\
\text { afternoon }\end{array}$ & pCORSI & $24.875 \pm 3.353$ & & \\
& BCI & $3.884 \pm 1.587$ & 0.63 & $\begin{array}{c}<0.01 \\
(2 \text {-tailed) }\end{array}$
\end{tabular}

\footnotetext{
${ }^{1}$ The arithmetic mean of the difference of the correct response of test test subjects for target stimulus.
}

Moreover, regarding the ${ }_{\mathrm{P}} \mathrm{CORSI}$ tests for examining short-term memory, between the morning $(M d n=96, D(32)=0.406 p<0.01$ (2-tailed)) and the afternoon $(M d n=88, D(32)=0.241 p<0.01$ (2-tailed)) results, a significant difference can be seen $(T=0 Z=-4.64 p<0.01$ (2-tailed) $r=0.83$ ).

According to the Wilcoxon signed-rank test results, during the short-term memory examination via the ${ }_{\mathrm{P}} \mathrm{CORSI}$ test, there is a significant difference in the results of the average level of attention measured by the BCI system ( $T=0 Z Z=-4.94 p<0.01$ (2-tailed) $r=0.87)$ in the morning $(M d n=54.35)$ and in the afternoon $(M d n=50.10)$ hours.

Figure 9a shows that the medians differ in comparing the two conditions; it can be seen that in the morning, the test subjects achieved better results. Data disposition is more likely to be seen above the median, while weaker results appeared in the afternoon from all aspects, moreover, data disposition from the median can be 
seen below the median. Figure $9 \mathrm{~b}$ shows that the medians differ in comparing the two conditions, it is generally apparent that the BCI system recorded higher level of attention on average in the morning and data disposition was slightly below the median. In the afternoon, the BCI system, regarding the average attention level, similarly to the results of the pCORSI test, shows a downturn, and data disposition is below the median.

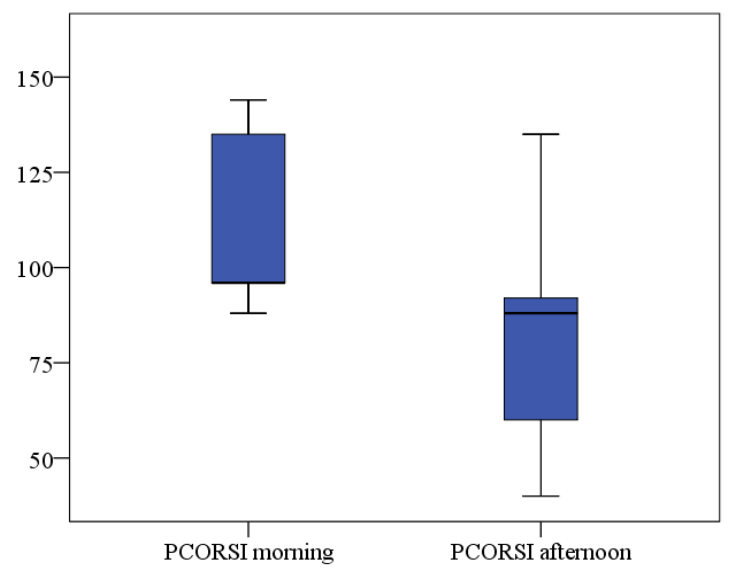

Figure 9a

There is a significant difference between the results of average attention level measured by the pCORSI in the morning and afternoon hours

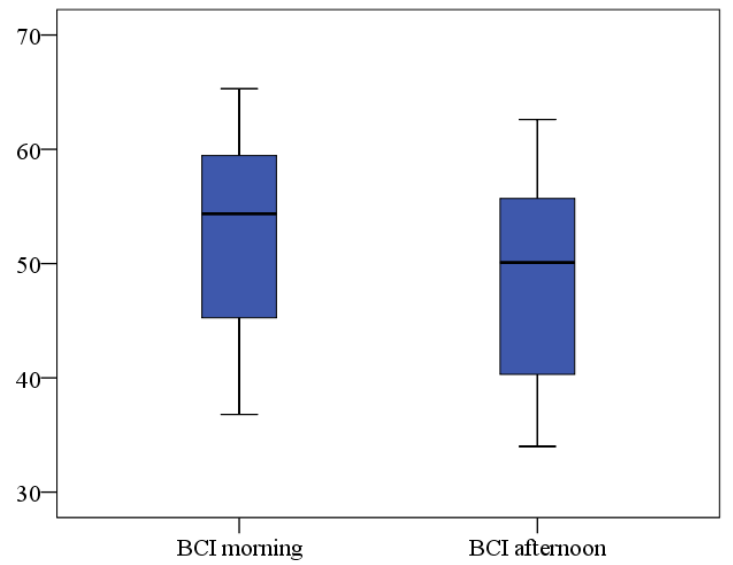

Figure $9 b$

There is a significant difference between the results of average attention level measured by the BCI system in the morning and afternoon hours 


\subsection{Comparing the Results of $\mathrm{PEBBINGHAUS}$ and $\mathrm{BCI}$}

The further aim of the examination and evaluation is to evaluate the correlation between two variables, a chosen outstanding result of the ${ }_{\mathrm{P}}$ EBBINGHAUS test and the average level of attention provided by the BCI system. The obtained correlations and relationships between the results of the test and the measurement provided by the BCI system can be estimated and evaluated on all samples, on all test subjects. The strength of the relationships was determined by an outstanding result of the ${ }_{\mathrm{p}} \mathrm{EBBINGHAUS}$ test, i.e., by one of the most typical parameters of the final test results. Spearman's correlation was used with two-sided tests to examine the correlation between individual measurements, since in case of the BCI variable, ordinal scale type was determined, and our data were monotonic. During the test, the difference between morning and afternoon results of the test subjects was evaluated to ensure that the differences in individual skills did not play role in the results of the learning test, only the different magnitude of attention in the morning and afternoon hours did.

In the ${ }_{\mathrm{p}} \mathrm{EBBINGHAUS}$ test on the efficiency of short-term memory, comparing the changes of the test results of alert and tired states to the change of the difference of the mean value, a characteristic of the level of attention determined by the data processed by the BCI system, it can be stated that a significant negative correlation can be shown (Fig. 10), where $r_{s}=-0.71 p<0.01$ (2-tailed).

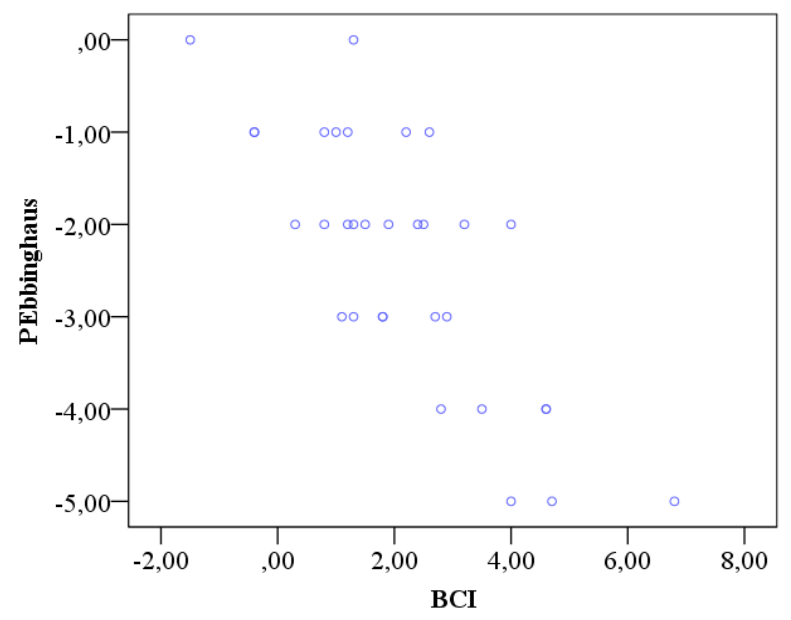

Figure 10

The ${ }_{\mathrm{p}} \mathrm{EBBINGHAUS}$ test results show a significant negative correlation with the value of difference of the level of average attention determined by the BCI 
More details of the evaluation of correlation can be seen in Table 2 .

Table 2

Spearman-correlation analysis for the whole sample $(\mathrm{N}=32)$ on the results of the ${ }_{\mathrm{P}} \mathrm{EBBINGHAUS}$ test and the difference of the mean value characteristic of the level of attention determined by the BCI

\begin{tabular}{ccccc}
\hline \hline Period & Test & $M \pm S D^{I}$ & Correlation & $p$-value \\
\hline $\begin{array}{c}\text { morning- } \\
\text { afternoon }\end{array}$ & PE. $^{2}$ & $-2.375 \pm 1.385$ & & $<0,01$ \\
& BCI & $2.141 \pm 1.724$ & -0.71 & $\begin{array}{c}<\text {-tailed }) \\
\end{array}$
\end{tabular}

\footnotetext{
${ }^{1}$ The arithmetic mean of the difference of the correct response of test test subjects for target stimulus.

${ }_{\mathrm{P}}^{2} \mathrm{EBBINGHAUS}$
}

In addition, in case of the ${ }_{\mathrm{P}} \mathrm{EBBINGHAUS}$ test, a significant difference $t(31)=-$ $9.70 p<0.01$ (2-tailed), $d=0.40$ could be found in the results of the morning $(M \pm S D=6.47 \pm 2.76$, and $D(32)=0.108 \quad p=0.200)$ and the afternoon $(M \pm S D=8.84 \pm 3.16$, and $D(32)=0.097 p=0.200)$ tests. According to the results of the Wilcoxon-signed rank test, regarding the ${ }_{\mathrm{p}} \mathrm{EBBINGHAUS}$ test, there is a significant difference $(T=6.17 Z=-4.59 p<0.01$ (2-tailed) $r=0.81$ ) as well between the results of the average level of attention measured by the BCI system in the morning $(M d n=55.10)$ and afternoon hours $(M d n=52.55)$.

As it can be seen in Fig. 11a, the medians differ comparing the two conditions. Overall, it is evident that in the morning the test subjects made fewer mistakes, data disposition rather appears below the median, while weaker results were achieved in the afternoon, and data disposition is below the median, too. Fig. 11b shows that the medians are different in comparison the two conditions. It can be seen that in the morning the BCI system recorded an average higher level of attention and data are distributed evenly around the median. In the afternoon, regarding the average level of attention, the BCI system, similarly to the results of the ${ }_{\mathrm{p}} \mathrm{EBBINGHAUS}$ test, shows a downturn, and data disposition is below the median. 


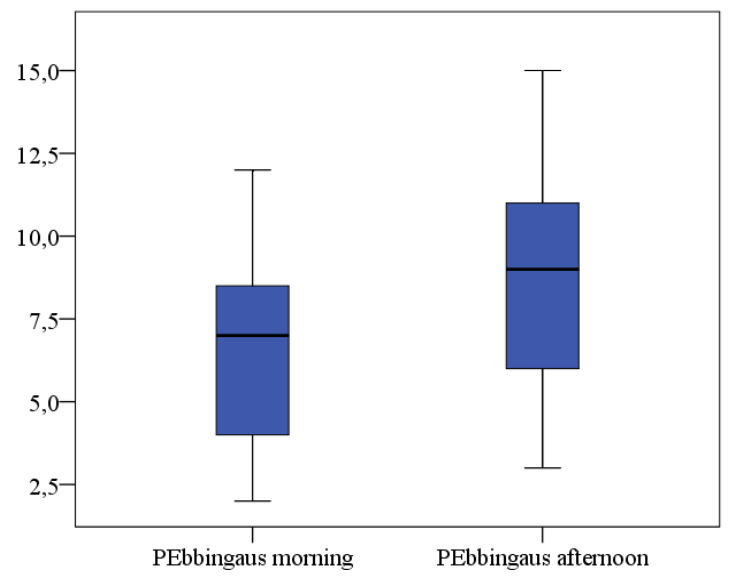

Figure 11a

There is a significant difference between pEbbinghaus test results for short-term memory in the morning and afternoon results

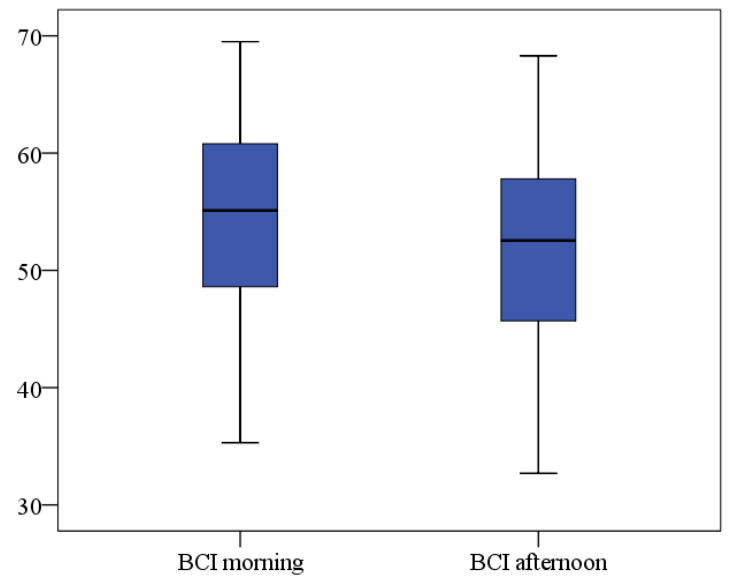

Figure 11b

There is a significant difference between the results of the BCI system for short-term memory in the morning and afternoon results

Similarly to the ${ }_{\mathrm{P}}$ CORSI test, it can be shown that the changes of the results of the ${ }_{\mathrm{p}}$ EBBINGHAUS learning test done in the more alert and tired states and the changes of the mean level of attention determined on the basis of the data processed by the BCI system are related to each other. In case of the ${ }_{\mathrm{p}} \mathrm{EBBINGHAUS}$ test, the magnitude of correlation is negative because the number of mistakes inversely proportional to the level of average attention were compared.

Since there is a cause-effect relationship according to the multiple spatial theory between attention and learning as a memorization, at a certain time the expectable 
success of learning can be concluded based on the level of attention. Relying on the statistical analysis of Table 1 and Table 2, the expectable efficiency of the ${ }_{\mathrm{p}}$ CORSI block and ${ }_{\mathrm{p}} \mathrm{EBBINGHAUS}$ memorization and learning tests can be concluded from the magnitude of the mean value characteristic of the level of attention provided by the BCI system. Consequently, the momentary learning ability of the test subject can be concluded.

From the given correlation values, we could see that there is a relatively high, over 0.6 , correlation between the test results of the learning efficiency tests and the average attention level measured by the EEG-based brain computer interface. This means that the implemented BCI system measuring method could be used as an alternative procedure besides the ${ }_{\mathrm{p}} \mathrm{CORSI}$ and ${ }_{\mathrm{p}} \mathrm{EBBINGHAUS}$ tests for measuring attention-based memorizing efficiency.

In general, at the lower level of concentration the measured values are lower and more unequable than at the higher concentration level measured ones, which are higher and harmonized.

\section{Conclusions}

It could be stated from the research data that the brain-computer interface attention values and the results of the memorizing tests have a significant relationship. According to this, in a given time interval we could indirectly conclude the expectable learning efficiency by the measured attention level. On the basis of the experiment topic, the research results and the given conclusions, it clearly seems that experiments based on the bioelectrical processes of the brain could open new areas of research and application in the future. With the help of a brain-computer interface test, attention level could be measured continuously in real time, which is one of the important influential factors in the learning process. With this information, the pedagogue could get continuous feedback about the level of attention of students. If it becomes lower, the information processing ability is lower as well and it makes a negative effect on memorizing. If these changes are recognised, the method of teaching could be changed or even a short relaxing break could be kept during the lesson, so instead of the traditionally structured lessons that start at a given time, last for a given time and finish in a given time, we could organize so-called students' attention level-synchronized lessons, in which the teaching of important curriculum and extra knowledge elements could be organized and reorganized according to the attention level of students even during a lesson. As the attention level changes, the hierarchy of learning, the organisation of the lessons could be changed. All in all, with this method the efficiency of teaching and studying could be increased and optimized besides opening new pedagogical approach and methodology in learning organization. 


\section{Acknowledgement}

This work is supported by the European Union, EFOP-3.6.1-16-2016-00003 project.

\section{References}

[1] E. Vaadia: Cognitive neuroscience: Learning how the brain learns, Nature, 2000, 405, pp. 523-525

[2] V. Calhoun, M. Amin, D. Hjelm, E. Damaraju and S. Plis: A deep-learning approach to translate between brain structure and functional connectivity, In Proceedings of the 2017 IEEE International Conference on Acoustics, Speech and Signal Processing (ICASSP 2017) New Orleans, United States, 2017, pp. 6155-6159

[3] A. Darden: Understanding How the Brain Learns Should Inform Our Teaching Practices, Journal of Microbiology \& Biology Education, 2012, 13(2) pp. 202-203

[4] J. Gottlieb: Attention, Learning, and the Value of Information, Neuron, 2012, 76(2) pp. 281-295

[5] E. Eldar, J. Cohen, and Y. Niv: The effects of neural gain on attention and learning, Nature Neuroscience, 2013, 16(8) pp. 1146-1153

[6] T. O. Zander and C. Kothe: Towards passive brain-computer interfaces: applying brain-computer interface technology to human-machine systems in general, Journal of Neural Engineering, 2011, 8(2) p. 025005

[7] M. A. Lebedev and M. A. L. Nicolelis: Brain-machine interfaces: past, present, and future, Trends in Neurosciences, 2006, 29(9) pp. 536-546

[8] Y. Li and C. Nam: Collaborative Brain-Computer Interface for People with Motor Disabilities [Research Frontier] IEEE Computational Intelligence Magazine, 2016, 11(3) pp. 56-66

[9] H. Hsu, I. Lee, H. Tsai, H. Chang, K. Shyu, C. Hsu, H. Chang, T. Yeh, C. Chang and P. Lee: Evaluate the Feasibility of Using Frontal SSVEP to Implement an SSVEP-Based BCI in Young, Elderly and ALS Groups, IEEE Transactions on Neural Systems and Rehabilitation Engineering, 2016, 24(5) pp. 603-615

[10] K. Ullah, M. Ali, M. Rizwan and M. Imran: Low-cost single-channel EEG based communication system for people with lock-in syndrome, In Proceedings of the 2011 IEEE $14^{\text {th }}$ International Multitopic Conference (INMIC 2011) Karachi, Pakistan, 2011, pp. 120-125

[11] G. Pfurtscheller, G. Muller-Putz, R. Scherer, and C. Neuper: Rehabilitation with Brain-Computer Interface Systems, Computer, 2008, 41(10) pp. 58-65

[12] W. Kaysa, Suprijanto and A. Widyotriatmo: Design of Brain-computer interface platform for semi-real-time commanding electrical wheelchair 
simulator movement, In Proceedings of the $20133^{\text {rd }}$ International Conference on Instrumentation Control and Automation (ICA 2013) Ungasan, Indonesia, 2013, pp. 39-44

[13] M. Choubisa and P. Trivedi: Analysing EEG signals for detection of mind awake stage and sleep deprivation stage, In Proceedings of the 2015 International Conference on Green Computing and Internet of Things (ICGCIoT 2015) Noida, India, 2015, pp. 1209-1211

[14] J. Katona: Examination and comparison of the EEG based attention test with CPT and TOVA, In Proceedings of the $15^{\text {th }}$ IEEE International Symposium on Computational Intelligence and Informatics (CINTI 2014) Budapest, Hungary, 2014, pp. 117-120

[15] M. Murugappan, R. Nagarajan and S. Yaacob: Appraising human emotions using Time-Frequency Analysis based EEG alpha band features, In Proceedings of the 2009 Innovative Technologies in Intelligent Systems and Industrial Applications (CITISIA 2009) Monash, Malaysia, 2009, pp. $70-75$

[16] C. Dongwei, W. Fang, W. Zhen, L. Haifang and C. Junjie: EEG-based emotion recognition with brain network using independent components analysis and granger causality, In Proceedings of the 2013 International Conference on Computer Medical Applications (ICCMA 2013) Sousse, Tunisia, 2013, pp. 1-6

[17] A. Vourvopoulos and F. Liarokapis: Robot Navigation Using BrainComputer Interfaces, In Proceedings of the 2012 IEEE $11^{\text {th }}$ International Conference on Trust, Security and Privacy in Computing and Communications (TrustCom 2012) Liverpool, UK, 2012, pp. 1785-1792

[18] J. Katona, T. Ujbanyi, G. Sziladi, and A. Kovari: Speed control of Festo Robotino mobile robot using NeuroSky MindWave EEG headset based Brain-Computer Interface, In Proceedings of the $7^{\text {th }}$ IEEE International Conference on Cognitive Infocommunications (CogInfoCom 2016) Wroclaw, Poland, 2016, pp. 251-256

[19] J. Katona, A. Kovari: EEG-based Computer Control Interface for BrainMachine Interaction, International Journal of Online Engineering, 2015, 11(6) pp. 43-38

[20] K. LaFleur, K. Cassady, A. Doud, K. Shades, E. Rogin and B. He: Quadcopter control in three-dimensional space using a noninvasive motor imagery-based brain-computer interface, Journal of Neural Engineering, 2013, 10(4) p. 046003

[21] J. Katona, A. Kovari: A Brain-Computer Interface Project Applied in Computer Engineering, IEEE Transaction on Education, 2016, 59(4) pp. 319-324 
[22] K. Watanabe, H. Tanaka, K. Takahashi, Y. Niimura, K. Watanabe, and Y. Kurihara: NIRS-Based Language Learning BCI System, IEEE Sensors Journal, 2016, 16(8) pp. 2726-2734

[23] Y. Tomita, F. Vialatte, G. Dreyfus, Y. Mitsukura, H. Bakardjian and A. Cichocki: Bimodal BCI Using Simultaneously NIRS and EEG, IEEE Transactions on Biomedical Engineering, 2014, 61(4) pp. 1274-1284

[24] N. Weiskopf, K. Mathiak, S. Bock, F. Scharnowski, R. Veit, W. Grodd, R. Goebel and N. Birbaumer: Principles of a Brain-Computer Interface (BCI) Based on Real-Time Functional Magnetic Resonance Imaging (fMRI), IEEE Transactions on Biomedical Engineering, 2014, 51(6) pp. 966-970

[25] F. E. Bloom, A. Lazerson: Brain, Mind, and Behavior, New York, NY: W. H. Freeman and Company, $3^{\text {rd }}$ edition, 2005, pp. 1-457

[26] G. Buzsaki: Rhythms of the brain, Oxford University Press, 2011, pp. 1448

[27] M. Scanziani, M. Häusser: Electrophysiology in the age of light, Nature, 2009, 461, pp. 930-939

[28] D. L. Schomer and F. L. da Silva: Niedermeyer's Electroencephalography: Basic Principles, Clinical Applications, and Related Fields, New York, Lippincot Williams \& Wilkins, $6^{\text {th }}$ ed., 2010, pp. 1-1296

[29] F. S. Tyner, J. R. Knott, and W. B. Mayer Jr.: Fundamentals of EEG Technology: Vol. 1: Basic Concepts and Methods, USA, Lippincott Williams \& Wilkins, $1^{\text {st }}$ ed., 1983, pp. 1-332

[30] F. H. Duffy, J. R. Hughes, F. Miranda, P. Bernad, P. Cook: Status of Quantified EEG (QEEG) in Clinical Practice, Clinical Electroencephalography, 1994, 25(4) pp. 6-22

[31] W. Sałabun: Processing and spectral analysis of the raw EEG signal from the MindWave, Przeglad Elektrotechniczny, 2014, 90(2) pp. 169-174

[32] NeuroSky: Brain Wave Signal (EEG) of NeuroSky, NeuroSky Inc., 2009

[33] Scientifics Direct, Inc. (2014, Dec. 10): NeuroSky MindWave - EEG Brain Wave Activities [Online] Available: http://www.scientificsonline.com/product/neurosky-mindwave

[34] NeuroSky: MindWave User Guide, NeuroSky Inc., 2011

[35] K. Montor: Attention-level analyzer, U.S. Patent 3877 466, April 15, 1975

[36] M. Murugappan, S. Murugappan, Balaganapathy, C. Gerard: Wireless EEG signals based Neuromarketing system using Fast Fourier Transform (FFT), In Proceedings of 2014 IEEE $10^{\text {th }}$ International Colloquium on Signal Processing \& its Applications (CSPA 2014) Kuala Lumpur, Malaysia, 2014, pp. 25-30 
[37] M. Murugappan, S. Murugappan: Human emotion recognition through short time Electroencephalogram (EEG) signals using Fast Fourier Transform (FFT), In Proceedings of 2013 IEEE $9^{\text {th }}$ International Colloquium on Signal Processing \& its Applications (CSPA 2013) Kuala Lumpur, Malaysia, 2013, pp. 289-294

[38] S. T. Muller, B. J. Piper: The Psychology Experiment Building Language (PEBL) and PEBL Test Battery, Journal of Neuroscience Methods, 2014, 222, pp. 250-259

[39] J. Cooley, P. Lewis and P. Welch: The finite Fourier transform, IEEE Trans. Audio Electroacoustics, 1969, 17(2) pp. 77-85

[40] A. V. Oppenheim, R. W. Schafer and J. R. Buck: Discrete-time signal processing, Upper Saddle River, N.J.: Prentice Hall, 1999, pp. 1-897

[41] A. D. Baddeley: Working Memory, Clarendon Press, 1986. pp. 1-289

[42] K. Biró, Gy. Molnár, D. Pap, Z. Szüts: The Effects of Virtual and Augmented Learning Environments on the Learning Process in Secondary School, Proceedings of $8^{\text {th }}$ IEEE International Conference on Cognitive Infocommunications (CogInfoCom 2017) Debrecen, Hungary, 2017, pp. $371-375$

[43] I. Horváth: Innovative engineering education in the cooperative VR environment, Proceedings of $7^{\text {th }}$ IEEE International Conference on Cognitive Infocommunications (CogInfoCom 2016) Wroclaw, Poland, 2016, pp. 359-364

[44] I. Horváth: Disruptive technologies in higher education, Proceedings of $7^{\text {th }}$ IEEE International Conference on Cognitive Infocommunications (CogInfoCom 2016) Wroclaw, Poland, 2016, pp. 347-352

[45] E. Gogh, A. Kovacs, G. Sziladi: Application of E-diary to analyze the effectiveness of learning, Proceedings of $8^{\text {th }}$ IEEE International Conference on Cognitive Infocommunications (CogInfoCom 2017) Debrecen, Hungary, 2017, pp. 419-422

[46] I. Horváth: The IT device demand of the edu-coaching method in the higher education of engineering, Proceedings of $8^{\text {th }}$ IEEE International Conference on Cognitive Infocommunications (CogInfoCom 2017) Debrecen, Hungary, 2017, pp. 379-384

[47] Z. Kvasznicza: Teaching electrical machines in a 3D virtual space, Proceedings of $8^{\text {th }}$ IEEE International Conference on Cognitive Infocommunications (CogInfoCom 2017) Debrecen, Hungary, 2017, pp. 385-388

[48] A. D. Kovács: The application opportunities of green roof, as an interactive educational space, Proceedings of $8^{\text {th }}$ IEEE International Conference on 
Cognitive Infocommunications (CogInfoCom 2017) Debrecen, Hungary, 2017, pp. 389-393

[49] A. Kutikova, J. Balata, Z. Mikovec: Explorations into ICT Usage and Behavior in Travel Related Activities of Wheelchair Users, Proceedings of $8^{\text {th }}$ IEEE International Conference on Cognitive Infocommunications (CogInfoCom 2017) Debrecen, Hungary, 2017, pp. 231-236

[50] M. Tariq, L. Uhlenberg, P. Trivailo, K. S Munir, and M. Simic: Mu-Beta Rhythm ERD/ERS Quantification for Foot Motor Execution and Imagery Tasks in BCI Applications, Proceedings of $8^{\text {th }}$ IEEE International Conference on Cognitive Infocommunications (CogInfoCom 2017) Debrecen, Hungary, 2017, pp. 91-96

[51] A. Kovács, I. Winkler, K. Vicsi: EEG correlates of speech: examination of event-related potentials elicited by phoneme classes, Proceedings of $8^{\text {th }}$ IEEE International Conference on Cognitive Infocommunications (CogInfoCom 2017) Debrecen, Hungary, 2017, pp. 115-120

[52] D. Geszten, B. P. Hámornik, K. Hercegfi: Measurement of team mental model as a part of a new team usability testing method, Proceedings of $8^{\text {th }}$ IEEE International Conference on Cognitive Infocommunications (CogInfoCom 2017) Debrecen, Hungary, 2017, pp. 291-294

[53] P. Baranyi, A. Csapo and Gy. Sallai: Cognitive Infocommunications (CogInfoCom) Springer, 2015

[54] P. Baranyi, A. Csapo: Definition and Synergies of Cognitive Infocommunications, Acta Polytechnica Hungarica, Vol. 9, No. 1, 2012, pp. 67-83

[55] G. Kiss, et al.: Connection between body condition and speech parametersespecially in the case of hypoxia, Proceedings of $5^{\text {th }}$ IEEE International Conference on Cognitive Infocommunications (CogInfoCom 2014) Vietri sul Mare, Italy, 2014, pp 333-336

[56] Lambrechts, et al.: Temporal dynamics of speech and gesture in Autism Spectrum Disorder, Proceedings of $5^{\text {th }}$ IEEE International Conference on Cognitive Infocommunications (CogInfoCom 2014) Vietri sul Mare, Italy, 2014, pp. 349-353

[57] A. K. Varga, and L. Czap.: Development of an online subjective evaluation system for recorded speech of deaf and hard of hearing children, Proceedings of $5^{\text {th }}$ IEEE International Conference on Cognitive Infocommunications (CogInfoCom 2015) Győr, Hungary, 2015, pp. 455458

[58] D. Sztahó, M. Gábriel Tulics, K. Vicsi, I. Valálik: Automatic Estimation of Severity of Parkinson's Disease Based on Speech Rhythm Related Features, Proceedings of $8^{\text {th }}$ IEEE International Conference on Cognitive 
Infocommunications (CogInfoCom 2017) Debrecen, Hungary, 2017, pp. $11-16$

[59] L. Izsó: The significance of cognitive infocommunications in developing assistive technologies for people with non-standard cognitive characteristics: CogInfoCom for people with nonstandard cognitive characteristics, Proceedings of $5^{\text {th }}$ IEEE International Conference on Cognitive Infocommunications (CogInfoCom 2015) Győr, Hungary, 2015, pp. 77-82

[60] R. Sperandeo, E. Moretto, G. Baldo, S. Dell'Orco, N. M. Maldonato: Executive Functions and Personality Features: a Circular Interpretative Paradigm, Proceedings of $8^{\text {th }}$ IEEE International Conference on Cognitive Infocommunications (CogInfoCom 2017) Debrecen, Hungary, 2017, pp. 63-66

[61] G. Wilcock, K. Jokinen: Bringing Cognitive Infocommunications to small language communities, Proceedings of $8^{\text {th }}$ IEEE International Conference on Cognitive Infocommunications (CogInfoCom 2017) Debrecen, Hungary, 2017, pp. 259-264

[62] F. Alam, M. Danieli, G. Riccardi: Can We Detect Speakers' Empathy? A Real-Life Case Study, Proceedings of the $7^{\text {th }}$ IEEE International Conference on Cognitive Infocommunications (CogInfoCom 2016) Wroclaw, Poland, 2016, pp. 59-64

[63] C. Vogel, M. R. Lopes, A. Esposito: Gender differences in the language of the Map Task dialogues, Proceedings of $8^{\text {th }}$ IEEE International Conference on Cognitive Infocommunications (CogInfoCom 2017) Debrecen, Hungary, 2017, pp. 151-156

[64] S. Pieskä, M. Luimula, H. Kaartinen, P. Qvist, T. Suominen, O. Tuusvuor: Multidisciplinary Wow Experiences Boosting SMEi, Proceedings of the $7^{\text {th }}$ IEEE International Conference on Cognitive Infocommunications (CogInfoCom 2016) Wroclaw, Poland, 2016, pp. 309-316

[65] O. Matarazzo, B. Pizzini, C. Greco, M. Carpentieri: Effect of a Chance Task Outcome on the Offers in the Ultimatum Game: The Mediation Role of Emotions, Proceedings of the $7^{\text {th }}$ IEEE International Conference on Cognitive Infocommunications (CogInfoCom 2016) Wroclaw, Poland, 2016, pp. 295-300

[66] M. G. Tulics, K. Vicsi: Phonetic-class based correlation analysis for severity of dysphonia, Proceedings of $8^{\text {th }}$ IEEE International Conference on Cognitive Infocommunications (CogInfoCom 2017) Debrecen, Hungary, 2017, pp. 21-26

[67] I. Schmitt, G. Wirsching, R. Römer, M. Wolff: Denormalized Quantum Density Operators for Encoding Semantic Uncertainty in Cognitive Agents, Proceedings of $8^{\text {th }}$ IEEE International Conference on Cognitive 
Infocommunications (CogInfoCom 2017) Debrecen, Hungary, 2017, pp. $165-170$

[68] A. Hayakawa, C. Vogel, N. Campbell, S. Luz: Perception changes with and without a video channel: A study from a speech-to-speech, machine translation mediated map task, Proceedings of $8^{\text {th }}$ IEEE International Conference on Cognitive Infocommunications (CogInfoCom 2017) Debrecen, Hungary, 2017, pp. 401-406

[69] Michael Beetz; Matthias Scheutz; Fereshta Yazdani: Guidelines for improving task-based natural language understanding in human-robot rescue teams, Proceedings of $8^{\text {th }}$ IEEE International Conference on Cognitive Infocommunications (CogInfoCom 2017) Debrecen, Hungary, 2017, pp. 203-208

[70] M. Koutsombogera, C. Vogel: Ethical Responsibilities of Researchers and Participants in the Development of Multimodal Interaction Corpora, Proceedings of $8^{\text {th }}$ IEEE International Conference on Cognitive Infocommunications (CogInfoCom 2017) Debrecen, Hungary, 2017, pp. 277-282

[71] A, Moró, Gy. Szaszák: A prosody inspired RNN approach for punctuation of machine produced speech transcripts to improve human readability, Proceedings of $8^{\text {th }}$ IEEE International Conference on Cognitive Infocommunications (CogInfoCom 2017) Debrecen, Hungary, 2017, pp. 219-224

[72] B. Radostyan, K. D.Pomazi, L. Gazdi, B. Forstner, L. Szegletes: Adaptive Figural Abstraction Test with Generated Exercises, Proceedings of the $7^{\text {th }}$ IEEE International Conference on Cognitive Infocommunications (CogInfoCom 2016) Wroclaw, Poland, 2016, pp. 327-330

[73] F. R. Izullah, M. Koivisto, A. Aho, T. Laine, H. Hämäläinen, P. Qvist, A. Peltola, P. Pitkäkangas, M. Luimula: NeuroCar Virtual Driving Environment - Simultaneous Evaluation of Driving Skills and Spatial Perceptual-attentional Capacity, Proceedings of the $7^{\text {th }}$ IEEE International Conference on Cognitive Infocommunications (CogInfoCom 2016) Wroclaw, Poland, 2016, pp. 31-36

[74] B. Lewandowska-Tomaszczyk, P. Wilson: Compassion, Empathy and Sympathy Expression Features in Affective Robotics, Proceedings of the $7^{\text {th }}$ IEEE International Conference on Cognitive Infocommunications (CogInfoCom 2016) Wroclaw, Poland, 2016, pp. 65-70

[75] J. Irastorza, M. I. Torres: Analyzing the expression of annoyance during phone calls to complaint services, Proceedings of the $7^{\text {th }}$ IEEE International Conference on Cognitive Infocommunications (CogInfoCom 2016) Wroclaw, Poland, 2016, pp. 103-106 
[76] Gy. Kovacs, T. Grosz, T. Varadi: Topical Unit Classification Using Deep Neural Nets and Probabilistic Sampling, Proceedings of the $7^{\text {th }}$ IEEE International Conference on Cognitive Infocommunications (CogInfoCom 2016) Wroclaw, Poland, 2016, pp. 199-204

[77] M. Rusko, M. Finke: Using Speech Analysis in Voice Communication A new approach to improve Air Traffic Management Security, Proceedings of the $7^{\text {th }}$ IEEE International Conference on Cognitive Infocommunications (CogInfoCom 2016) Wroclaw, Poland, 2016, pp. 181-186

[78] D. Balla, T. Mester, Á. Botos, T. J. Novák, M. Zichar, J. Rásó, A. Karika: Possibilities of spatial data visualization with web technologies for cognitive interpretation, Proceedings of $8^{\text {th }}$ IEEE International Conference on Cognitive Infocommunications (CogInfoCom 2017) Debrecen, Hungary, 2017, pp 17-20

[79] P. Qvist, N. B. Trygg, M. Luimula, A. Peltola, T. Suominen, V. Heikkinen, P. Tuominen, O. Tuusvuor: Demo: Medieval Gastro Box - Utilizing VR Technologies in Immersive Tourism Experience, Proceedings of the $7^{\text {th }}$ IEEE International Conference on Cognitive Infocommunications (CogInfoCom 2016) Wroclaw, Poland, 2016, pp. 77-78

[80] D. Nguyen, G. Bailly, Frederic Elisei: Conducting neuropsychological tests with a humanoid robot: design and evaluation, Proceedings of the $7^{\text {th }}$ IEEE International Conference on Cognitive Infocommunications (CogInfoCom 2016) Wroclaw, Poland, 2016, pp. 337-342

[81] V. Sarathy, M. Scheutz, B. Malle: Learning behavioral norms in uncertain and changing contexts, Proceedings of $8^{\text {th }}$ IEEE International Conference on Cognitive Infocommunications (CogInfoCom 2017) Debrecen, Hungary, 2017, pp. 301-306

[82] S. Savić, M. Gnjatovic, D. Mišković, J. Tasevski, N. Maček: CognitivelyInspired Symbolic Framework for Knowledge Representation, Proceedings of the $7^{\text {th }}$ IEEE International Conference on Cognitive Infocommunications (CogInfoCom 2016) Wroclaw, Poland, 2016, pp. 315-320

[83] C. Rigóczki, D. Andrei, and K. Györgyi-Ambró: Gamification on the edge of educational sciences and pedagogical methodologies, Journal of Applied Technical and Educational Sciences, Vol. 7, No. 4, pp. 79-88, Nov. 2017

[84] K.D. Pomazi, L. Gazdi, B. Radostyan, B. Forstner, L. Szegletes: SelfStandardizing Cognitive Profile Based on Gardner's Multiple Intelligence Theory, Proceedings of the $7^{\text {th }}$ IEEE International Conference on Cognitive Infocommunications (CogInfoCom 2016) Wroclaw, Poland, 2016, pp. 317 322

[85] L. Major: The model of the environmental attitude of teacher candidates, Journal of Applied Technical and Educational Sciences, Vol. 8, No. 1, pp. 25-35, Apr. 2018 
[86] M. Szabo, K. D. Pomazi, B. Radostyan, L. Szegletes, B. Forstner: Estimating Task Difficulty in Educational Games, Proceedings of the $7^{\text {th }}$ IEEE International Conference on Cognitive Infocommunications (CogInfoCom 2016) Wroclaw, Poland, 2016, pp. 397-402

[87] A. Csapo, A. Kristjansson, H. Nagy, Gy. Wersenyi: Evaluation of HumanMyo Gesture Control Capabilities in Continuous Search and Select Operations, Proceedings of the $7^{\text {th }}$ IEEE International Conference on Cognitive Infocommunications (CogInfoCom 2016) Wroclaw, Poland, 2016, pp. 415-420

[88] A. Esposito, A. M. Esposito, M. Maldonato, C. Vogel: Differences between hearing and deaf subjects in decoding foreign emotional faces, Proceedings of $8^{\text {th }}$ IEEE International Conference on Cognitive Infocommunications (CogInfoCom 2017) Debrecen, Hungary, 2017, pp. 175-180

[89] J. Henshaw, W. Liu, D. Romano: Improving SSVEP-BCI Performance Using Pre-Trial Normalization Methods, Proceedings of $8^{\text {th }}$ IEEE International Conference on Cognitive Infocommunications (CogInfoCom 2017) Debrecen, Hungary, 2017, pp. 247-252

[90] S. Ondas, L.Mackova, D. Hladek: Emotion Analysis in DiaCoSk Dialog Corpus, Proceedings of the $7^{\text {th }}$ IEEE International Conference on Cognitive Infocommunications (CogInfoCom 2016) Wroclaw, Poland, 2016, pp. 151156

[91] L. Gazdi, K. D. Pomazi, B. Radostyan, B. Forstner, L. Szegletes: Experimenting with classifiers in biofeedback-based mental effort measurement, Proceedings of the $7^{\text {th }}$ IEEE International Conference on Cognitive Infocommunications (CogInfoCom 2016) Wroclaw, Poland, 2016, pp. 331-336

[92] M. Meier, M. Borsky, E. H. Magnusdottir, K. R. Johannsdottir, J. Gudnason: Vocal tract and voice source features for monitoring cognitive workload, Proceedings of the $7^{\text {th }}$ IEEE International Conference on Cognitive Infocommunications (CogInfoCom 2016) Wroclaw, Poland, 2016, pp. 97-102

[93] R. Vassiliki, D. Arfani, K. Fragkopoulou, E. Danasi, S. Varlokosta, G. Paliouras: Automatic detection of linguistic indicators as a means of early detection of Alzheimer's disease and of related dementias: A computational linguistics analysis, Proceedings of $8^{\text {th }}$ IEEE International Conference on Cognitive Infocommunications (CogInfoCom 2017) Debrecen, Hungary, 2017, pp. 33-38

[94] A. Ghosh, E. Stepanov, M. Danieli, G. Riccardi: Are You Stressed? Detecting High Stress from User Diaries, Proceedings of $8^{\text {th }}$ IEEE International Conference on Cognitive Infocommunications (CogInfoCom 2017) Debrecen, Hungary, 2017, pp. 265-270 
[95] M. Gnjatović, J. Tasevski, D. Mišković, S. Savić, B. Borovac, A. Mikov,R. Krasnik: Pilot Corpus of Child-Robot Interaction in Therapeutic Settings, Proceedings of $8^{\text {th }}$ IEEE International Conference on Cognitive Infocommunications (CogInfoCom 2017) Debrecen, Hungary, 2017, pp. 253-258

[96] A. Mecocci, F. Micheli, C. Zoppetti, A. Baghini: Automatic Falls Detection in Hospital-Room Context, Proceedings of the $7^{\text {th }}$ IEEE International Conference on Cognitive Infocommunications (CogInfoCom 2016) Wroclaw, Poland, 2016, pp. 127-132 